\title{
A natureza da ciência e a formação de professores: um diálogo necessário
}

Flávio Tajima Barbosa

tajima.barbosa@gmail.com Universidade Federal do Paraná (UFPR), Curitiba, Paraná, Brasil

\section{Joanez Aparecida Aires}

joanez@ufpr.br Curitiba, Paraná, Brasil

\section{RESUMO}

A Natureza da Ciência ( $\mathrm{NdC}$ ) é entendida como um dos aspectos mais fundamentais no que diz respeito à construção, ao estabelecimento e à organização do conhecimento científico. Refere-se, de uma maneira geral, à epistemologia e à sociologia da Ciência, aos valores e às crenças inerentes ao conhecimento científico e seu desenvolvimento. Procuramos destacar neste artigo o fato de que a formação de professores poderia dar foco à importância do entendimento da NdC para o ensino de Ciências, bem como as habilidades necessárias para o desenvolvimento dessa abordagem. Acreditamos que para realçar o conteúdo pedagógico relacionado à $\mathrm{NdC}$, os professores necessitam de oportunidades para reflexão e discussão sobre as questões da $\mathrm{NdC}$ e orientações práticas para o ensino da NdC. Assim, o objetivo deste artigo é discutir as possibilidades de se incluir reflexões referentes à $\mathrm{NdC}$ nos cursos de formação de professores, procurando apresentar caminhos possíveis para essa integração. Apresentamos de modo breve o projeto europeu History and Philosophy in Science Teaching (HIPST), um caso de sucesso na utilização de tal abordagem. Ao introduzir reflexões epistemológicas na formação inicial e continuada de professores, deseja-se romper com um pensamento de Ciência largamente hegemônico, cuja base pode ser encontrada nas filosofias positivistas e cujo dogma consiste na transmissão de verdades científicas definitivas e neutras. Acreditamos que o ato de refletir sobre a própria prática constitui-se no momento em que o professor pensa sobre si mesmo enquanto educador, e assim constrói uma visão crítica de sua prática, transformando-a.

PALAVRAS-CHAVE: Natureza da Ciência. História da Ciência. Formação de professores. Ensino de Ciências. 


\section{INTRODUÇÃO}

A tradição cultural científica contemporânea ainda privilegia a visão da Ciência como uma coleção de fatos e conteúdos tidos como "verdades" absolutas sobre os fenômenos naturais. O conhecimento científico não é tomado, nas escolas, como uma construção contextualizada sócio-historicamente, que se mostra dinâmica e que afeta e é afetada pelo seu tempo, mas sim como um saber estático, definitivo e dogmático. Consequentemente, as aulas de Ciências oferecem pouco espaço para discussões e diálogos e, como resultado, os alunos, de modo geral, veem a Ciência como um corpo de conhecimento caracterizado por fatos a serem aprendidos e com menos "margem de erro" (HÖTTECKE; SILVA, 2011).

Acreditamos que para haver uma mudança no modo como a Ciência é ensinada e para que as aulas de Ciências se tornem uma atividade mais próxima daquilo que os cientistas realmente fazem, os alunos poderiam conhecer aspectos relacionados aos fatores que influenciam o desenvolvimento dos conceitos científicos. E, para isso, questões relativas à Natureza da Ciência ( $\mathrm{NdC}$ ) poderiam estar mais presentes nas salas de aula. Dessa maneira, os alunos compreenderiam o conjunto de elementos que tratam da construção, estabelecimento e organização do conhecimento científico.

A NdC, segundo Lederman (2006, p. 4), refere-se aos "preceitos epistemológicos subjacentes às atividades da Ciência e às características do conhecimento resultante". Sendo assim, estudar a NdC significa "compreender como o homem constrói o conhecimento científico em cada contexto e em cada época, tendo como base suas concepções filosóficas, ideológicas e metodológicas". (MOURA, 2014, p. 37).

A finalidade de se abordar a NdC é que os estudantes possam desenvolver uma base conceitual que os permita compreender a natureza das teorias científicas. Dessa forma, a sala de aula, segundo Höttecke, Henke e Riess (2012), pode ser um espaço para discussões e negociações de ideias, juntamente com os procedimentos de geração e avaliação de evidências científicas. Assim, as aulas de Ciência poderiam enfatizar atividades mais centradas nos alunos, e não tanto no professor, já que dessa maneira, aqueles assumiriam uma posição mais ativa no processo de ensino e aprendizagem, e não apenas receberiam o conhecimento transmitido pelo professor.

No entanto, alguns obstáculos ainda impedem que haja uma mudança educacional: a estrutura organizacional tradicional das escolas, o ensino centrado no professor, a falta de conhecimentos e habilidades dos professores, a resistência à mudança que alguns apresentam devido principalmente à idade, à experiência e ao aprendizado acadêmico são alguns impeditivos ainda presentes nas instituições educacionais (HENKE; HÖTTECKE, 2015).

A mudança pedagógica que buscamos em relação ao modo como o conhecimento científico é apresentado exige uma compreensão sólida da $\mathrm{NdC}$ que se deseja ensinar, pois os professores não mudarão suas atitudes enquanto acreditarem que a Ciência é um conjunto de verdades, descobertas por cientistas, e que saber Ciência é memorizar e repetir estas verdades ou parte delas.

Matthews (1995) salienta que a postura teórica do professor sobre a NdC pode ser transmitida de forma explícita ou implícita, influenciando a visão que o aluno 
formará a respeito do que seja a Ciência. O professor sempre transmitirá ao aluno uma visão de Ciência, por mais que não esteja consciente de tal ato.

Segundo Maldaner (2006), a imagem que muitos professores têm da Ciência é a de uma aproximação progressiva a uma verdade preexistente à qual se chegará, mais cedo ou mais tarde, pela observação e medidas sempre mais rigorosas. Os professores em geral confundem os objetos teóricos e as idealizações com os objetos reais da Ciência. E assim, essa é a imagem de Ciência que os professores apresentam aos alunos, mesmo que de maneira implícita, já que a concepção que muitos professores possuem é construída a partir de um conhecimento tácito e não reflexivo. É importante que o professor compreenda, conforme ressalta Maldaner (2006), que as produções científicas fazem parte de uma realidade criada, e não se confundem com os objetos reais da Ciência.

Porém, esse tipo de reflexão não faz parte da formação de professores, e estes acabam sendo influenciados por posições positivistas, que prevalecem em toda sua formação, e que se perpetuarão em sua vida profissional. Assim, segundo Maldaner (2006, p. 108), "reflexões epistemológicas devem contemplar o conhecimento científico produzido como sistema conceitual coerente e poderoso de agir sobre o mundo concreto para modificá-lo e recriá-lo".

Dessa maneira, o objetivo deste artigo é discutir sobre a necessidade de se incluir reflexões sobre a NdC nos cursos de formação de professores, procurando apresentar caminhos possíveis para essa integração. Ao introduzir reflexões epistemológicas na formação inicial e continuada de professores, deseja-se romper com um pensamento de Ciência largamente hegemônico, cuja base pode ser buscada nas filosofias positivistas, com a tentativa de transmissão de verdades científicas definitivas e neutras. Acreditamos com isso possibilitar o professor construir uma visão crítica de sua prática, transformando-a.

\section{ASPECTOS CONSENSUAIS SOBRE A NDC}

A busca pelas características essenciais que definem o conhecimento científico tem sido objeto de pesquisa de filósofos, historiadores, sociólogos e educadores de Ciências que veem nos aspectos consensuais da $\mathrm{NdC}$ um possível subsídio para tornar as aulas de Ciências mais ricas e atraentes. Tais aspectos têm como objetivo ensinar aos alunos de Ciências o modo como o conhecimento científico é construído, fundando-se, para tanto, nos pontos em que há consenso entre os epistemólogos da Ciência. Nesse sentido, estudar a NdC no contexto contemporâneo, segundo Tala e Vesterinen (2015), dá ao estudante condições para que possa interpretar a Ciência de seu tempo, permitindo compreender as aplicações científicas em sua vida cotidiana, participar de discussões públicas sobre a Ciência atual, bem como avaliar o seu impacto na sociedade.

Segundo McCain (2015), as várias disciplinas científicas assemelham-se muito na confiança em evidências, no uso de hipóteses e teorias, na lógica utilizada, dentre outros aspectos. $\mathrm{O}$ autor ainda salienta que as diferentes Ciências se utilizam, em algum momento, de evidências empíricas na explicação de um fenômeno, que devem incluir informações precisas sobre o fenômeno que pretende explicar. Além disso, as disciplinas científicas, em certo ponto, utilizam 
leis para dar explicações. Em vista disso é que se pode utilizar o conceito de "aspectos consensuais da NdC" para descrever o que vem a ser a Ciência.

Gil-Pérez et al. (2001, p. 35) categorizaram uma série de tópicos que foram definidos como "características essenciais do trabalho científico", sendo considerados como elementos essenciais da $\mathrm{NdC}$ e que fornecem subsídios para que uma imagem não distorcida da Ciência seja veiculada. Observam que, apesar das divergências, há aspectos comuns às diferentes vertentes do pensar sobre a Ciência, tratando-se então de "evitar que algumas árvores nos impeçam de ver a floresta".

Os autores citam como aspectos consensuais o fato de que o conhecimento científico tem como característica o pluralismo metodológico, não havendo um único método científico, sendo as hipóteses os guias para a experimentação. 0 ceticismo em relação aos resultados obtidos também é um pressuposto básico do cientista, que busca encontrar uma coerência global nas explicações que desenvolve, procurando abarcar o maior número de fenômenos possíveis. E deve se atentar ainda que na tentativa de compreender como um fato foi originado, o contexto pode ser analisado de modo a evitar reducionismos. (GIL-PÉREZ et al., 2001).

Segundo Forato, Pietrocola e Martins, algumas concepções da NdC que são importantes para a formação de professores e alunos incluem

[...] a compreensão da Ciência como uma atividade humana; entender a Ciência se desenvolvendo em um contexto cultural de relações humanas; conhecer sobre as Ciências e não apenas os conteúdos científicos; possibilitar certo conhecimento metodológico como um antídoto à interpretação empírico-indutivista da Ciência. (FORATO; PIETROCOLA; MARTINS, 2011, p. 32-33).

Os autores acreditam que esses preceitos sejam básicos para que se possa compreender a NdC. Em oposição ao que geralmente é veiculado nos livros didáticos, onde os cientistas aparecem como grandes homens que em momentos de insight e isolamento fazem grandes descobertas, a imagem de Ciência que pode ser construída é aquela em que o contexto social exerce influência sobre o cientista. Este, enquanto ser humano e, portanto, sujeito a erros, usa a criatividade e a imaginação na formulação de hipóteses e é também influenciado por outros cientistas, outras ideias, já que não vive num mundo à parte, sendo o empreendimento científico, sobretudo, um empreendimento social. Nesse sentido é que se faz importante o conhecimento dos processos do fazer científico e não apenas seus produtos.

\section{UMA PERSPECTIVA HUMANÍSTICA PARA O ENSINO DE CIÊNCIAS}

Segundo Vesterinen e Aksela (2013), a discussão de dimensões epistemológicas e sociológicas das Ciências causa estranhamento aos professores que ainda não estão familiarizados com essa abordagem. Uma das razões para tal estranhamento talvez se dê pelo fato de que ensinar utilizando a $\mathrm{NdC}$ e outras perspectivas humanísticas não esteja em alinhamento com a imagem que os professores possuem do que seja o Ensino de Ciências e, portanto, a NdC é vista como algo separado das metas da educação científica. Na visão dos professores, 
de acordo com as autoras, os conhecimentos e habilidades necessários para a implementação da abordagem com a NdC talvez estejam mais relacionados com uma cultura de ensino da área de humanas do que com a área científica. Como bem ressalta Lederman (2006), os professores têm uma tendência a gastar menos tempo ensinando aquilo que não valorizam, e sendo assim, por mais que compreendam a NdC, talvez não a ensinem a seus estudantes. A formação de professores pode, portanto, valorizar o fato de que não se trata de apenas mais um conteúdo a ser ensinado, e sim, uma mudança de atitude frente à Ciência.

No entanto, a relação entre compreender a $\mathrm{NdC}$ e a sua implementação no Ensino de Ciências não é simples. Vesterinen e Aksela (2013) observam que um ganho conceitual a respeito da $\mathrm{NdC}$ não leva necessariamente a sua utilização no planejamento das aulas nem ao uso em sala. Para que haja uma adequação dos entendimentos sobre a $\mathrm{NdC}$ em sala de aula, os professores necessitam de preparo no que se refere ao conteúdo pedagógico relacionado à $\mathrm{NdC}$. Ainda segundo estes autores, um conhecimento pedagógico consolidado permitiria aos professores falar confortavelmente sobre questões da NdC, conduzir discussões, responder rapidamente e apropriadamente às questões, esclarecer equívocos, dar bons exemplos etc.

Nota-se, assim, que "a simples incorporação de disciplinas de conteúdos epistemológicos não implica na sua automática utilização pelo futuro professor em suas aulas ou na promoção de uma visão mais abrangente de Ciência". (MOURA, 2012 , p. 84). Não basta estruturar cuidadosa e fundamentalmente um currículo se o professor não receber um preparo adequado para aplicá-lo. A utilização de uma nova abordagem para os conteúdos tradicionais requer do professor uma mudança de mentalidade em relação ao que se espera que o estudante aprenda. Se o que se pretende é que o aluno tenha uma compreensão mais ampla sobre os processos de desenvolvimento do conhecimento científico, o problema não se resolve apenas proporcionando aos professores instruções mais detalhadas, por meio de manuais ou cursos de formação continuada. Antes, faz-se necessário uma profunda revisão da formação acadêmica inicial e permanente.

A formação de professores poderia enfatizar a importância do entendimento da NdC para o ensino, e as habilidades necessárias para o desenvolvimento dessa abordagem. Para realçar o conteúdo pedagógico relacionado à NdC, os professores necessitam de oportunidades para reflexão e discussão sobre as questões da NdC e orientações práticas para o ensino da NdC. (VESTERINEN; AKSELA, 2013).

Compreender a hesitação, ou mesmo a recusa dos professores em ensinar com a NdC é um pré-requisito para a superação dos obstáculos ainda presentes na utilização desta abordagem, já que a atitude do professor frente a alguma inovação curricular pode impedir ou potencializar o seu processo de implementação. Assim, de acordo com Höttecke e Riess (2009), os esforços para a implementação da HFC não podem ignorar as perspectivas dos professores, suas crenças sobre o ensino e a aprendizagem, seus objetivos, sua compreensão epistemológica e suas dúvidas sobre a relevância da NdC.

Em uma pesquisa realizada sobre um curso de $\mathrm{NdC}$ para professores de Química, Vesterinen e Aksela (2013) relatam que aquele forneceu aos professores novas perspectivas sobre a Química, um novo panorama conceitual para pensar e discutir sobre a pesquisa científica, e os possibilitou unir os diferentes modelos e 
teorias da disciplina em um todo mais coerente. Os autores ainda destacam que conhecer os aspectos centrais de $\mathrm{NdC}$ é importante como parte do conhecimento geral ou como um recurso para o ensino.

Assim, os cursos que discutem aspectos da NdC poderiam utilizar diferentes argumentos sobre a importância do entendimento público da Ciência e das dimensões da alfabetização científica, de modo que fornecessem aos professores um panorama que justificasse a inclusão de dimensões filosóficas, históricas e sociológicas entre os objetivos da educação científica. Dessa maneira, deve haver, segundo Vesterinen e Aksela (2013), uma associação entre o entendimento dos professores a respeito da NdC e suas crenças em relação ao Ensino de Ciências, além de discussões sobre as razões e justificativas para a sua inserção na educação científica.

Nesse sentido, existem inúmeros desafios relacionados ao desenvolvimento de conhecimento de conteúdo pedagógico relacionado à $\mathrm{NdC}$, como: o fato de não se saber a melhor forma de utilização de tal abordagem; os materiais instrucionais serem poucos, inadequados ou inexistentes e os conhecimentos e as habilidades dos professores em relação ao tema serem insatisfatórios. (VESTERINEN; AKSELA, 2013).

Silva (2014) analisou algumas das Instituições de Ensino de Superior (IES) que apresentam em seu currículo disciplinas que, supostamente, podem subsidiar discussões sobre a NdC aos futuros professores de Física, devido ao seu caráter de cunho histórico-filosófico. O autor investigou o entendimento dos alunos de Licenciatura em Física, da Universidade Federal do Piauí, no que diz respeito à inserção da História e Filosofia da Ciência (HFC) na sala de aula e, principalmente, se eles são motivados à elaboração de estratégias didáticas embasadas nela. Analisando a ementa do curso, que tem a finalidade de narrar um longo trecho da História da Física em um curto espaço de tempo, concluiu que durante o curso faltam momentos oportunos para discussão de fatores historiográficos, didáticos e metodológicos que auxiliem o professor que pretende inserir a HFC na sala de aula de forma adequada. $\mathrm{O}$ autor sugere a necessidade de discussões com os futuros professores de aspectos do conjunto de obras históricas produzidas por historiadores ao longo do tempo e de tipos de fontes de pesquisa e principais vícios historiográficos, os quais possibilitem, dentre outros pontos, a identificação de problemas em textos encontrados em livros, materiais didáticos e, principalmente, na internet, como também de aspectos relacionados à epistemologia da Ciência. Dessa maneira, segundo o autor, o professor terá ferramentas adequadas para orientá-lo na escolha dos textos históricos que serão empregados em sala de aula e, principalmente, incentivar seu uso de forma correta.

Sendo assim, se o intuito é trabalhar a NdC na formação de professores, permitindo uma visão mais abrangente do tema, é necessário que os professores tenham uma formação que os permitam conhecer a $\mathrm{NdC}$ em seus diversos aspectos. Além das disciplinas relacionadas ao tema, é preciso que os professores tenham a oportunidade de refletir sobre como incorporar essa abordagem em suas aulas. Dessa maneira, "não basta que tenhamos disciplinas de $\mathrm{NdC}$ nas licenciaturas. É preciso refletir sobre o como fazer". (MARTINS, 2007 apud MOURA, 2012 , p. 83). Procuraremos logo abaixo, dar um exemplo de como esta prática pode tornar-se factível. 


\section{TRAÇANDO UM CAMINHO: O PROJETO HISTORY AND PHILOSOPHY IN SCIENCE TEACHING (HIPST)}

$\mathrm{Na}$ tentativa de solucionar alguns dos problemas referentes ao desenvolvimento e implantação do ensino de Ciências com a abordagem História e Filosofia da Ciência (HFC), que tem como um dos pontos centrais a NdC, a União Europeia fundou, em 2008, o projeto de History and Philosophy in Science Teaching (HIPST), que inclui 10 parceiros de 7 países europeus. O projeto tem como pressupostos básicos métodos centrados no aluno, como aprendizagem investigativa, experimentos com réplicas, discussões semiestruturadas e atividades de dramatização (HÖTTECKE; RIESS, 2009). De acordo com estes autores, atividades como experimentação, observações e discussões são estratégias muito promissoras, de acordo com estudos que levaram em consideração o interesse dos alunos em HFC.

Por outro lado, atividades como ler ou ouvir textos podem facilmente se tornar experiências passivas, com pouco potencial para atrair a atenção dos alunos (HÖTTECKE; HENKE; RIESS, 2012). Estes autores defendem atividades centradas no aluno, de modo a permitir que este se envolva de maneira ativa no processo de ensino-aprendizagem, discutindo, argumentando e defendendo algum ponto de vista, propiciando o desenvolvimento de um pensamento criativo, reflexivo e autônomo. Argumentam que isto pode ser alcançado por meio de atividades que possibilitem ao estudante um envolvimento maior com a geração e avaliação das evidências científicas. Também salientam que, ao se usar a HFC, há que se justificar claramente o uso dessa abordagem para os alunos, sendo que eles devem entender que

\footnotetext{
O estudo de conhecimentos do passado compreende aquilo que os cientistas já tomaram como sendo válido, útil e apropriado, e que, ainda assim, foram criticados ao longo do tempo. Entretanto, conhecer a Ciência passada e o seu desenvolvimento histórico pode nos ajudar a compreender o conhecimento científico atual e as razões para crer que o conhecimento atual é válido, útil e apropriado. (HÖTTECKE; HENKE; RIESS, 2012, p.1.237, tradução nossa).
}

O projeto HIPST visa ao desenvolvimento de materiais que auxiliem no ensino do conteúdo científico, tomando como base a epistemologia, os processos e os contextos da Ciência. Para tanto, utiliza o desenvolvimento de estudos de caso históricos para o processo de ensino e aprendizagem. $O$ estudo de caso histórico se caracteriza por princípios gerais que possibilitem o resgate do contexto em que se deu algum problema marcante na ciência.

Segundo Höttecke e Riess (2009), o conceito de ensino e aprendizagem com estudos de caso considera a Ciência de maneira detalhada, a fim de destacar aspectos gerais da epistemologia, do conteúdo científico e da $\mathrm{NdC}$. Os estudos de caso podem ser utilizados dentro de uma abordagem narrativa, focando em uma história juntamente com uma ideia central. Os autores ressaltam que, assim, possibilitam expandir a visão de alunos e professores para além dos conteúdos e produtos da Ciência, de modo que possa ser vislumbrado o fazer científico e o contexto em que são realizados.

Höttecke, Henke e Riess (2012) destacam a importância de se contextualizar historicamente os experimentos, as teorias, os modelos e as habilidades específicas do cientista ou de seus ajudantes. Também enfatizam a necessidade de 
se mostrar a inter-relação existente entre sociedade, cultura e Ciência. Esta pode ser apresentada como uma construção humana e social, incluindo perspectivas das motivações dos cientistas, conflitos e controvérsias entre diferentes teorias. Os autores destacam que o projeto considera a Ciência como um processo não-linear, um empreendimento caracterizado por desvios e erros contrabalanceados por soluções criativas e uma natureza autocorretiva. No projeto HIPST, o aluno é levado a aprender Ciência em um contexto histórico, e sendo assim, o foco do ensino se altera. $\mathrm{O}$ aprendizado deixa de ser apenas relacionado à aquisição de conhecimento e passa a focar nos processos de se fazer Ciência.

No entanto, deve-se levar em consideração que tanto o aluno como o professor estão habituados com os padrões tradicionais de Ensino de Ciências, onde o conhecimento científico é apresentado como "verdadeiro". Essa questão merece ser levada em consideração, já que, segundo Höttecke, Henke e Riess (2012), não é provável que os alunos aceitem essa perspectiva sem nenhuma resistência. Antes de estimarem a importância que a abordagem histórica e epistemológica representa para o seu próprio aprendizado, e não a verem como uma perda de tempo, os estudantes devem ser levados a ter o máximo possível de experiências proveitosas com a HFC. Esta é uma das principais razões pelas quais os autores consideram que o desenvolvimento de atividades centradas no aluno é importante para o ensino com a abordagem HFC.

Dentre as atividades centradas no aluno desenvolvidas no projeto HIPST estão o ensino com réplicas de experimentos históricos e o aprendizado por investigação direcionada. Höttecke, Henke e Riess (2012) salientam que atividades que proporcionem uma reflexão explícita sobre a $\mathrm{NdC}$ são consideradas como centrais para que os alunos compreendam os processos da construção do conhecimento científico. Nessa perspectiva, o papel dos experimentos é crucial, já que a História da Ciência oferece ótimos exemplos que podem servir como guias para que os estudantes desenvolvam os próprios experimentos, e os comparem com aqueles descritos pelos cientistas do passado. Fontes históricas como cartas, anotações de diários de laboratório ou artigos dos cientistas constituem-se em instrumentos que auxiliam nas experimentações e na elaboração de respostas às questões que surgirem durante o processo investigativo.

As réplicas de experimentos históricos apresentam como vantagens o alto grau de autenticidade e a contextualização. Por meio das réplicas, os alunos são levados a aprender habilidades práticas e a manipular materiais, associando a isso uma compreensão teórica do instrumento e também do fenômeno em estudo. Durante o experimento, as observações realizadas e os dados gerados devem ser interpretados, dando ensejo a reflexões sobre a natureza das observações e o papel dos instrumentos na geração de novos conhecimentos na Ciência.

Dentro do projeto, ainda segundo Höttecke, Henke e Riess (2012), os professores apresentam os tópicos gerais que serão trabalhados em sala de aula, juntamente com várias atividades de investigação apropriadas. São os professores quem decidem o contexto histórico no qual as atividades serão inseridas, e é partir da questão de pesquisa que envolve este contexto que os alunos iniciam suas atividades, que são elaboradas e planejadas pelos próprios estudantes. Eles são auxiliados em seu trabalho e na interpretação dos resultados pelo material de instruções e pela orientação do professor. 
O projeto HIPST visa a um modelo de ensino no qual os interesses, as ideias prévias e as crenças do aluno a respeito de um determinado conteúdo científico são explorados. Este contexto é então analisado, classificado e estruturado de acordo com as necessidades dos alunos. 0 modelo de ensino que o projeto se propõe a realizar não é uma mera redução a algum conteúdo científico ou a algum conteúdo da História ou Filosofia da Ciência. O que os autores do projeto defendem é uma reconstrução dos aspectos científicos, históricos e filosóficos sob uma perspectiva educacional.

Sendo assim, o Ensino de Ciências pode trazer aos alunos reflexões e problematizações sobre a Ciência, buscando ressaltar que o conhecimento científico é construído em um espaço e tempo específicos, sendo estes fatores algumas vezes determinantes nesse processo. As salas de aula, conforme ressaltam Vital e Guerra (2014), precisam se tornar espaços de questionamentos, e não de transmissão unilateral do conhecimento científico. O aluno pode compreender o problema existente em se adotar uma visão de Ciência linear e cumulativa, algorítmica, distante dos problemas sociais e realizado apenas por grandes gênios. Para tanto, o contato com as controvérsias históricas pode auxiliar nesse processo, levando o aluno a compreender a pluralidade dos métodos científicos, o papel da criatividade na elaboração de teorias e como o pensamento divergente produz muitas ideias e desenvolve muitas possibilidades a partir de um único ponto de partida.

\section{A HISTÓRIA DA CIÊNCIA COMO ARTICULADOR DE DISCUSSÕES SOBRE A NDC}

Segundo Londero (2015), o objetivo da abordagem com a HFC é engajar os estudantes no que diz respeito às ideias que trazem à sala de aula, motivando discussões e fazendo com que levem em consideração explicações alternativas, de modo que compreendam como as teorias são criadas. Uma questão importante que se dá quando o professor conhece a NdC está em poder compreender as ideias dos seus alunos, pois inúmeras vezes, o raciocínio encontrado em sala de aula é muito semelhante àquele que um dia a Ciência já considerou como correto. No entanto, segundo Tolvanen et al. (2014), é importante destacar que as ideias dos alunos acerca dos fenômenos, que muitas vezes se dá de maneira intuitiva, e aquelas explicações dadas por cientistas no passado não podem ser vistas como idênticas, já que enquanto os estudantes se esforçam em aprender a Ciência, os cientistas do passado se esforçavam para criar aquela Ciência. A confrontação entre teorias já ultrapassadas e aquelas aceitas atualmente pela comunidade científica, possibilita que os alunos compreendam questões pertinentes relacionadas à $\mathrm{NdC}$.

Dessa maneira, a História da Ciência não é apenas um complemento ao conteúdo, mas o ponto central para o entendimento de conceitos, tanto científicos como da NdC. O entendimento de como os conceitos foram construídos ao longo da história facilita o aprendizado de sua concepção final.

Em vista disso é crucial a discussão e adoção de novas abordagens para o estudo da História da Ciência, de modo que promova o desenvolvimento dos cursos de formação de professores de Ciências. Essas novas abordagens "devem evidenciar o caráter dinâmico da Ciência, menos autoritário e construído com a colaboração de homens e mulheres comuns que trabalharam para sua 
consolidação" (MOURA, 2012, p. 91). Nessa mesma perspectiva, também é possível trabalhar a questão dos materiais didáticos, incentivando atividades que preparem os futuros professores a elaborarem seus próprios materiais, a partir da consulta adequada de fontes primárias e secundárias, sempre levando em conta os perigos das distorções históricas. (TOLVANEN et al., 2014; FORATO; MARTINS; PIETROCOLA, 2011).

De acordo com Forato, Pietrocola e Martins (2011), o uso da História da Ciência no Ensino de Ciências exige cautela, já que qualquer narrativa histórica encerra uma visão da Ciência e dos processos de sua construção. O principal problema, segundo os autores, é que nos ambientes educacionais ainda são encontradas reconstruções históricas de cunho empírico-indutivista ingênua sobre a construção da Ciência. Interpretações descontextualizadas também são um problema, já que narrativas que analisam o passado anacronicamente, com valores, ideias e crenças de outra época, são geralmente preconceituosas, "selecionando e enaltecendo conceitos e teorias 'similares' aos aceitos no presente". (FORATO; PIETROCOLA; MARTINS, 2011, p. 37). Dessa forma, os autores apontam três elementos que merecem ser considerados na escolha de determinado conteúdo histórico que vise elucidar questões relativas à NdC: "o tema histórico deve favorecer os objetivos epistemológicos pretendidos, deve estar adequado ao ambiente educacional em questão, e deve contemplar aspectos viáveis para as possibilidades do professor poder tratar o tema adequadamente" (FORATO; PIETROCOLA; MARTINS, 2011, p. 44).

De acordo com Guerra, Braga e Reis (2013), as aulas de Ciências do Ensino Médio devem incluir discussões de elementos da $\mathrm{NdC}$ que não apresentem divergências entre os especialistas, permitindo que os estudantes desenvolvam ideias apropriadas sobre a Ciência. Reconhecem que as características de cada época ou episódio científico podem ser realçadas para os estudantes, de modo que estes compreendam que a Ciência é um "sistema de conhecimento construído por indivíduos incorporados em um contexto sociocultural". (GUERRA; BRAGA; REIS, 2013, p. 1487, tradução nossa). Os autores descrevem um trabalho onde implementaram um projeto pedagógico utilizando uma abordagem históricofilosófica da Ciência. Para tanto, eles selecionaram seis temas que podiam ser ensinados independentemente, com um cientista histórico representando cada tema. O propósito era enfatizar o contexto de cada personagem, ao invés de sua biografia. Foram desenvolvidos materiais que incorporassem diálogos e discussões entre os cientistas, bem como controvérsias histórico-filosóficas do período. Os autores salientam que o propósito de tal projeto não foi ensinar o conteúdo apresentado, e sim contextualizar o desenvolvimento de cada tema.

Na visão dos autores, os estudantes tendem a apreciar mais a Ciência caso os professores utilizem uma abordagem histórico-filosófica que guie as discussões a respeito de um dado conteúdo científico. Assim, elucida-se a interação entre Ciência e sociedade e enfatiza-se que a construção do conhecimento científico ocorre por meio de diálogos e disputas entre diferentes escolas de pensamento. Os autores ainda sugerem que os professores discutam os limites da Ciência e sua capacidade para responder questões levantadas pelos cientistas ao longo da história, reforçando a ideia de que os cientistas não se encontram isolados da sociedade. 
Segundo Tolvanen et al. (2014), uma vez que os estudantes estejam familiarizados com os fatos históricos, eles se tornam mais receptivos ao aprendizado de detalhes mais complexos do fato científico e também das questões associadas à NdC. O uso de múltiplos exemplos de teorias e investigações tiradas da História da Ciência pode auxiliar os estudantes a compreenderem o que exemplos distintos possuem em comum em se tratando de NdC.

Experimentos também podem ser utilizados numa abordagem histórica. $\mathrm{O}$ experimento por si só questiona, interroga, problematiza, conduz, muitas vezes, a outras hipóteses. A experiência é uma atividade que envolve muitas ideias, muitos tipos de compreensões, bem como muitas capacidades. Como bem ressaltam Arruda, Silva e Laburú (2001), a teoria não se relaciona com os fatos, em função de sua verificação ou falseamento, mas em vista de sua adaptação. Para tanto, compreender o experimento como adequação empírica da teoria, e também como guia da continuação da sua construção ou complementação é essencial para que se compreenda a relação existente entre teoria e experimento.

A realização de experimentos históricos pode auxiliar nesse processo, já que para realizá-los é necessário que antes se conheça a teoria subjacente à construção daqueles instrumentos, bem como sua função na construção da teoria. Os experimentos históricos permitem, portanto, que o aluno conheça a História da Ciência fazendo Ciência. Sendo assim, o aluno pode ser levado a compreender que o experimento não é uma mera ilustração da teoria.

Além disso, segundo Tolvanen et al. (2014), utilizar réplicas de experimentos históricos permite que os estudantes compreendam o papel da experiência na História da Ciência e na produção de conhecimento. As réplicas podem ser tanto históricas quanto físicas, sendo que nas primeiras, o experimento é repetido utilizando equipamentos os mais autênticos possíveis, enquanto que nas réplicas físicas, são utilizados equipamentos modernos. Utilizar experimentos históricos pode ajudar os estudantes a entenderem os processos de produção do conhecimento científico.

Selecionar episódios da História da Ciência contribui para tornar mais significativas questões aparentemente simples da Ciência e, como consequência, promover uma visão mais adequada do processo de construção do conhecimento científico. Pode-se assim, desvendar quais foram as complicações e os obstáculos epistemológicos que tiveram que ser superados, o que constitui uma ajuda imprescindível para compreender as dificuldades dos alunos e também como evoluíram os referidos conhecimentos, evitando visões estáticas e dogmáticas que deformam a natureza do trabalho científico (CARVALHO; GIL-PÉREZ, 2011).

\section{CONSIDERAÇÕES FINAIS}

Este artigo teve como objetivo discutir sobre a necessidade de se incluir reflexões sobre a $\mathrm{NdC}$ nos cursos de formação de professores. Levando em consideração a complexidade do tema e o modo como se pode abordá-lo no Ensino de Ciências, soa irreal pensar que um único curso de formação de professores possa transformar completamente as atitudes e crenças a respeito do Ensino de Ciências que os professores possuem. Tais crenças e atitudes muitas vezes são produtos de uma escola de cultura científica com crenças bastante 
tradicionais sobre o ensino e aprendizado. Assim, como a reflexão possui um papel central na mudança de tais crenças, faz-se fundamental que se pense acerca da cultura do Ensino de Ciências, não apenas por algumas semanas, mas durante todo o curso de formação. Dessa maneira, os professores formadores podem fazer esforços para que discussões a respeito dos aspectos epistemológicos e sociológicos da Ciência estejam presentes em várias etapas do ciclo de formação. Estudar a História da Ciência é, dessa forma, colocar o professor como parte desta história, aperfeiçoando sua postura crítica e ativa em relação à Ciência.

No entanto, por mais que os professores tenham algum contato com a História da Ciência, é utópico esperar que eles estejam completamente preparados para trabalhar com a história, filosofia e sociologia da Ciência. Nesse sentido, os professores podem começar com pequenos casos históricos para ensinar aspectos centrais da NdC, e assim, desenvolver competências adequadas para o uso de abordagens históricas.

Ao se problematizar episódios históricos da Ciência, os professores podem fazer com que os alunos tenham uma compreensão mais abrangente da Ciência e das questões envolvidas em sua construção. Nesse sentido, a problematização de acontecimentos históricos implica que estes não sejam abordados como uma simples coleção de anedotas, como é bastante comum encontrarmos nos livros didáticos, mas como uma reunião de elementos a serem colocados em discussão. Ao se problematizar episódios históricos, são extraídos pontos que podem ser tratados como problemas.

Contornar a falta de preparo dos professores no que diz respeito a habilidades em HFC é uma das tarefas para uma maior implementação desta abordagem no Ensino de Ciências. Prepará-los para identificar, analisar e então questionar certas manifestações anacrônicas, além dos conteúdos específicos da HFC, é uma das etapas necessárias para tal concretização

Concluímos ressaltando que as mudanças necessárias para uma efetiva implementação da $\mathrm{NdC}$ na educação científica precisam ir além dos muros da escola, de modo que fatores externos como os documentos oficiais, livros didáticos e vestibulares também enfatizem a importância da história, filosofia e sociologia da Ciência no Ensino de Ciências. As propostas baseadas na NdC devem, além disso, alcançar nível nacional para realmente atingir as mudanças tão caras ao ensino. 


\title{
The nature of science and teacher formation: a necessary dialogue
}

\begin{abstract}
The Nature of Science $(\mathrm{NdC})$ is understood as one of the most fundamental aspects regarding the construction, establishment and organization of scientific knowledge. It refers, in a general way, to the epistemology and sociology of Science, to the values and beliefs inherent in scientific knowledge and its development. In this article, we emphasize the fact that teacher formation could focus on the importance of $\mathrm{NdC}^{\prime} \mathrm{s}$ understanding of science teaching, as well as the skills needed to develop such an approach. We believe that in order to highlight the pedagogical content related to $\mathrm{NdC}$, teachers need opportunities for reflection and discussion on $\mathrm{NdC}$ issues and practical guidance for $\mathrm{NdC}$ teaching as well. Thus, the objective of this article is to discuss the possibilities of including reflections on the $\mathrm{NdC}$ in teacher formation courses, seeking to present possible ways of such integration. We briefly present the European project History and Philosophy in Science Teaching (HIPST), a case of success in using such an approach. By introducing epistemological reflections into the initial and continuing formation of teachers, one wishes to break with a largely hegemonic science thought, the basis of which can be found in positivist philosophies, which dogma consists in the transmission of definitive and neutral scientific truths. We believe that the act of reflecting on one's own practice is the moment when the teacher thinks about himself as an educator, and thus constructs a critical view of his practice, transforming it.
\end{abstract}

KEYWORDS: Nature of Science. History of Science. Teacher Training. Science Teaching. 


\section{REFERÊNCIAS}

ARRUDA, S. M.; SILVA, M. R.; LABURÚ, C. E. Laboratório didático de Física a partir de uma perspectiva kuhniana. Investigações em Ensino de Ciências, Porto Alegre, v. 6, n. 1, p. 97-106, 2001.

CARVALHO, A. M. P.; GIL-PÉREZ, D. Formação de professores de Ciências: tendências e inovações. 10 ed. São Paulo: Cortez, 2011.

FORATO, T. C. M.; MARTINS, R. A.; PIETROCOLA, M. History and nature of science in high school: building up parameters to guide educational materials. Science and Education, v. 21, n. 5, p. 657-682, 2012.

FORATO, T. C. M.; PIETROCOLA, M.; MARTINS, R. A. Historiografia e natureza da Ciência na sala de aula. Caderno Brasileiro de Ensino de Física, Florianópolis, v. 28, n. 1, p. 27-59, 2011.

GIL-PÉREZ, D. et al. Para uma imagem não deformada do trabalho científico. Ciência \& Educação, Bauru, v. 7, n. 2, p. 125-153, 2001.

GUERRA, A.; BRAGA, M.; REIS, J. C. History, philosophy, and Science in a social perspective: a pedagogical Project. Science and Education, v. 22, p. 1485-1503, 2013.

HENKE, A.; HÖTTECKE, D. Physics teachers' challenges in using history and philosophy of Science in teaching. Science and Education, v. 24, p. 349-385, 2015.

HÖTTECKE, D.; HENKE, A.; RIESS, F. Implementing history and philosophy in Science teaching: strategies, methods, results and experiences from the European HIPST Project. Science and Education, v. 21, n. 9, p. 1.233-1.261, 2012.

HÖTTECKE, D.; RIESS, F. Developing and implementing case studies for teaching Science with the help of history and philosophy. Paper presented at the Tenth International History, Philosophy and Science Teaching Conference. South Bend, USA, 2009.

HÖTTECKE, D.; SILVA, C. C. Why implementing history and philosophy in school science education is a challenge: an analysis of obstacles. Science and Education, v. 20, n. 3-4, p. 293-316, 2011. 
LEDERMAN, N. G. Research on nature of science: Reflections on the past, anticipations of the future. Asia-Pacific Forum on Science Learning and Teaching, v. 7, n. 1, 2006.

LONDERO, L. A história e filosofia da Ciência na formação de professores de física: controvérsias curriculares. História da Ciência e Ensino: construindo interfaces, v. 11, p. 18-32, 2015.

MALDANER, O. A. A formação inicial e continuada de professores de química. 3. ed. Ijuí: Ed. Unijuí, 2006.

MATTHEWS, M. História, filosofia e ensino de Ciências: a tendência atual de reaproximação. Caderno Catarinense de Ensino de Física, Florianópolis, v. 12, n. 3, p. 164-214, dez. 1995.

McCAIN, K. Explanation and the nature of scientific knowledge. Science and Education, v. 24, p. 827-854, 2015.

MOURA, B. A. Formação crítico-transformadora de professores de Física: uma proposta a partir da História da Ciência. 2012. 309 f. Tese (Doutorado) Faculdade de Educação, Instituto de Física, Instituto de Química, Instituto de BioCiências, Universidade de São Paulo, São Paulo, 2012.

MOURA, B. A. O que é natureza da Ciência e qual sua relação com a história e filosofia da Ciência. Revista Brasileira de História da Ciência, v. 7, n. 1, p. 32-46, 2014.

SILVA, B. V. C. A história e filosofia da Ciência na formação dos professores: um estudo no curso de física da UFPI. Ciência \& Ideias, Nilópolis, v. 5, n.1, p. 39-50, 2014.

TALA, S.; VESTERINEN, V. Nature of Science contextualized: studying nature of Science with scientists. Science \& Education, v. 24, p. 435-457, 2015.

TOLVANEN, S. et al. How to use historical approach to teach nature of Science in chemistry education? Science and Education, v. 23, p. 1.605-1.636, 2014.

VESTERINEN, V.; AKSELA, M. Design of chemistry teacher education course of nature of science. Science \& Education, v. 22, p. 2.193-2.225, 2013. 
VITAL, A.; GUERRA, A. A natureza da Ciência no ensino de Física: estratégias didáticas elaboradas por professores egressos do mestrado profissional. Caderno Brasileiro de Ensino de Física, Florianópolis, v. 31, n. 2, p. 225-257, 2014.

Recebido: 30 jul. 2017

Aprovado: 20 jan. 2018

DOI: 10.3895/actio.v3n1.7093

Como citar:

BARBOSA, F. T.; AIRES, J. A. A natureza da ciência e a formação de professores: um diálogo necessário. ACTIO, Curitiba, v. 3, n. 1, p. 115-130, jan./abr. 2018. Disponível em: <https://periodicos.utfpr.edu.br/actio> Acesso em: XXX

Correspondência:

Flávio Tajima Barbosa

Rua Parintins, n. 198, ap. 22, Bairro Vila Izabel, Curitiba, Paraná, Brasil.

Direito autoral: Este artigo está licenciado sob os termos da Licença Creative Commons-Atribuição 4.0

Internacional.

(c) (1) 